\title{
ESTUDO DE CASO - EDUCAÇÃO CORPORAL INDIVIDUALIZADA
}

\author{
Celisa Laureano Prata Cardoso*
}

\section{RESUMO}

O presente estudo é o resultado de uma pesquisa, que tem como objetivo relatar, por meio de um trabalho de campo realizado no Centro de Trabalho Muscular e Postural nos anos de 1998 a 2002, princípios filosóficos em torno do ser humano, sua identidade e valor, a educação corporal integral, o repensar da prática e o alavancar de discussões acerca da ginástica individualizada. Neste contexto, o estudo traz sob uma nova ótica a importância do respeito à individualidade biológica, estrutural e emocional, na integração e construção de significados, que possam dar sentido à qualidade de vida.

PALAVRAS-CHAVE: Educação Corporal - Postural - Ambiente.

\section{INTRODUÇÃO}

O presente trabalho é uma pesquisa desenvolvida no Centro de Trabalho Muscular e Postural em Goiânia, na qual se utilizou a abordagem qualitativa e algumas quantificações, tendo o trabalho muscular e postural centrado no indivíduo, como norteador dos procedimentos metodológicos.

Este trabalho procura discutir uma tendência que há tempos figura dentro dos ambientes de atividade física, que são os trabalhos personalizados com grupos multidisciplinares, nos quais em muitos

* Pesquisadora, licenciada em Educação Física e Ciências Biológicas (Universidade Federal de Goiás); Mestranda em Biologia (Departamento de Biologia Geral - UFG); Analista em Cultura; Desportos e Ginástica na Prefeitura de Goiânia. 
momentos interagem educadores físicos, fisioterapeutas e nutricionistas, tendo como objetivo a educação corporal integral.

A educação corporal, dentro do contexto das profundas transformações no mundo do trabalho contemporâneo, nos condiciona a ritmos alimentares e rotinas de vida impostos pelo ambiente físico e o contextual, no qual nos encontramos inseridos. Rotinas estas que comprometem nossa qualidade integral de vida e limitam nossa expressividade, criatividade, sensibilidade e participação social no processo de transformação.

A Biologia e a Química servem como alicerce para a compreensão de quase todos os aspectos da nutrição, do exercício e da saúde (KATCH; MCARDLE, 1996), cerceadas por recursos da Antropologia, buscando, com uma visão multidisciplinar, a investigação do perfil em um indivíduo em um ambiente de atividade física. Ressalta-se que, como Daolio (1994), utilizaremos o chamado "olhar antropológico", o qual coloca em foco a atuação do indivíduo não em termos exclusivamente Biológicos, Químicos ou Antropológicos, mas num aspecto relacional que engloba a todos, já que na prática cotidiana o mesmo representa e constrói significados sobre essas áreas.

A estabilidade da massa corpórea e do aspecto geral de um indivíduo adulto e sadio esconde as grandes flutuações diárias do seu metabolismo. De fato, o hábito de ingerir alimentos por meio de refeições, submete o organismo humano a duas situações opostas que, gradativamente, se alternam: abundância e escassez de nutrientes (MARZZOCO; TORRES, 1990). Além disso, a diversidade de composição das refeições, a diversidade metabólica individual e os fatores culturais e emocionais implicam em uma variação qualitativa e quantitativa de absorção dos nutrientes recebidos. Conforme Tribastone (2001), isto demonstra que o indivíduo é uma síntese dinamicamente complexa, na qual o corpo e a psique se integram ou interagem, formando uma unidade psicofísica indissociável, única, inconfundível e irreproduzível.

Algumas vezes, este desequilíbrio de energia associado a fatores sócio-econômicos e culturais, impostos em função de novos ritmos alimentares e rotinas de vida, condicionados ao ambiente físico e ao contexto no qual estamos inseridos, compromete nossa qualidade de vida e nos proporciona, pela falta de exercício físico e ambiente adequado de trabalho, a aquisição de doenças e problemas estruturais, causados pela 
relação forma orgânica, função e história de vida. Tudo isto pode agravar ou causar alterações morfológicas estruturais (Tabela I) irreversíveis como os dimorfismos (TRIBASTONE, 2001).

I: FORMAS FUNCIONAIS - relativas aos sistemas neuromuscular ou cápsulo-ligamentar (reversíveis).

\begin{tabular}{|c|c|c|c|}
\hline $\begin{array}{l}\text { Alteração } \\
\text { Morfológica }\end{array}$ & Definição & Plasticidade & $\begin{array}{l}\text { Ginástica } \\
\text { Corretiva } \\
\text { (Terapêutica) }\end{array}$ \\
\hline $\begin{array}{l}\text { Distúrbios } \\
\text { Psicomotores }\end{array}$ & $\begin{array}{l}\text { a: o indivíduo não } \\
\text { conhece o próprio } \\
\text { corpo; } \\
\text { b: ele não sabe trabalhar } \\
\text { o próprio corpo; }\end{array}$ & Reversível & $\begin{array}{l}\text { Educação } \\
\text { Psicomotora }\end{array}$ \\
\hline $\begin{array}{l}\text { Maus Hábitos } \\
\text { Posturais }\end{array}$ & $\begin{array}{l}\text { a: o indivíduo não } \\
\text { adquiriu o controle } \\
\text { do próprio corpo; } \\
\text { b: o indivíduo perdeu } \\
\text { temporariamente o } \\
\text { controle do próprio } \\
\text { corpo; }\end{array}$ & Reversível & $\begin{array}{l}\text { Reeducação } \\
\text { Psicomotora }\end{array}$ \\
\hline Paramorfismos & $\begin{array}{l}\text { o indivíduo tem: “um } \\
\text { conjunto de hábitos } \\
\text { morf o ló g i c os } \\
\text { p ar a n o r m a is, } \\
\text { compreendidos } \\
\text { entre os limites da } \\
\text { normalidade e da } \\
\text { patologia". }\end{array}$ & Reversível & $\begin{array}{l}\text { Reeducação } \\
\text { Psicomotora }\end{array}$ \\
\hline \multicolumn{4}{|c|}{$\begin{array}{l}\text { II: FORMAS ESTRUTURAIS - Relativas ao sistema esquelético } \\
\text { (irreversíveis). }\end{array}$} \\
\hline Dimorfismos & $\begin{array}{l}\mathrm{O} \text { individuo tem } \\
\text { alter ações patológicas }\end{array}$ & Irreversível & $\begin{array}{l}\text { Ginástica } \\
\text { Ortopédica }\end{array}$ \\
\hline
\end{tabular}

Neste contexto, a atividade para grupos especiais / diferenciados vem sendo amplamente discutida, implantada e difundida em função 
dos resultados obtidos através de sua aplicação. Uma aplicação que prioriza o respeito da individualidade biológica, estrutural e emocional, em que o ambiente e a atividade são adaptados a estas limitações e especificidades, e busca na atividade humana, a construção e a integração de significados que possam dar sentido à vida.

Apesar de individualizada, a atividade física num ambiente em grupo permite ao indivíduo a troca de experiências e expectativas com o educador físico, que atua como um facilitador desta troca com o grupo e com o próprio grupo em um processo de valorização e busca conjunta da motivação pela auto-estima e educação para a percepção corporal. Conforme Freire (1991), a ação humana é a expressão de uma complexidade que, no humano, atinge um nível extremo, inclusive porque, a cada gesto, sua história e sua cultura são afirmadas. E descrever o homem se movimentando é descrever sua inteligência. Descrevê-lo em ato é descrever seus sentimentos, e assim por diante. E descrever a motricidade é descrever um sistema em funcionamento.

A ginástica personalizada, devidamente orientada, apresenta-se neste contexto como um valioso recurso para o bom equilíbrio do todo, representado pelo indivíduo, desde que além de bem orientada seja conquistada a persistência através da sensibilização e conscientização dos participantes, pois a ginástica é um recurso a longo prazo e como tal deve ser aplicada de forma sistemática, com gradação e progressiva em grau e número de exercícios (MERCÚRIO, 1997). Deve ser também observado o momento em que se encontra o indivíduo, flexibilizando seu programa de atividade física, em função de suas atividades diárias e tensões psicológicas que acabam resultando em tensão muscular.

\section{METODOLOGIA}

O levantamento de dados foi realizado no período de 1998 a 2002 e arquivado no Centro de Trabalho Muscular e Postural, onde foram correlacionados os problemas posturais detectados na avaliação fisioterápica, a idade e a atividade de trabalho. Foram analisados os problemas posturais mais frequientes, bem como o processo de estar aluna e a interação entre colegas na aplicação do trabalho, freqüência e persistência no tratamento.

O grupo de estudos constituiu-se de 128 mulheres, divididas confore 
Weineck (2000), tabela II, em sua maioria composto de sedentárias, esportistas esporádicas e esportistas não treinadas.

\begin{tabular}{|l|l|}
\hline \multicolumn{1}{|c|}{ FASE } & \multicolumn{1}{c|}{ IDADE } \\
\hline Adulta Precoce & $18 / 20-30$ anos \\
Adulta Média & $30-45 / 50$ anos \\
Adulta Posterior & $45 / 50-60 / 70$ anos \\
Adulta Tardia & A partir de $60 / 70$ anos \\
\hline
\end{tabular}

\section{APLICAÇÃO DO TRABALHO}

O trabalho foi desenvolvido de forma individualizada, num ambiente em grupo onde no momento da matrícula, em entrevista de avaliação com o educador físico, este solicita que se faça uma avaliação muscular e postural, com um profissional da área de fisioterapia, uma avaliação médica e, se necessário, em alguns casos como obesidade, gestação ou outros, solicita-se o acompanhamento de uma nutricionista, para redução, manutenção ou equilíbrio do peso (no caso de gestante).

Na ficha constam, além da faixa etária, o tempo de atividade física, a descrição sintética do problema postural e/ou motivo da busca pela atividade física personalizada, quem indicou (médico, amigo, parente) e os exercícios a serem desenvolvidos.

Os exercícios são repetidos por dez aulas, e na primeira aula a quantidade é determinada pela própria aluna, que irá realizar quantas repetições conseguir e a quantidade é anotada na ficha de acompanhamento. Nas aulas subseqüentes, o número de exercícios é aumentado de forma gradativa, sendo que os exercícios abdominais e de membros inferiores são realizados em duas, ou três séries, conforme a necessidade prevista em avaliação precedente e disponibilidade de tempo da aluna.

Esta disponibilidade de tempo se faz necessária para a execução de todos os exercícios propostos de forma tranqüila, possibilitando que as alunas se relacionem socialmente com as colegas e executem de forma correta e prazerosa todos os exercícios propostos. Quanto à execução, buscamos resgatar o prazer da prática esportiva, contudo, durante as atividades $80 \%$ relataram algum tipo de experiência dolorosa ou constrangedora nestas práticas. 
Após dez aulas acontece a troca dos exercícios objetivando a motivação e a mudança do estímulo em nível muscular, para que se mantenham os resultados obtidos, estudamos também uma constante combinação de exercícios buscando o aumento da coordenação motora, concentração e equilíbrio, além do fortalecimento e compensação das atividades de trabalho. $\mathrm{O}$ aumento das repetições, da carga (peso) e a troca de exercícios acontecem simultaneamente e de forma progressiva.

\section{RESULTADOS E DISCUSSÃO}

Constatou-se através da análise das fichas de acompanhamento das alunas no período de janeiro de 1998 a dezembro de 2002 uma baixa rotatividade destas e uma progressão no número de indicações junto ao grupo de convívio, um predomínio de procura e permanência por alunas das faixas etárias entre adulta média e adulta posterior conforme Weineck (2000) Tabela II.

Observou-se, também, que grande parte dos problemas morfofuncionais acontece em função das alterações posturais adquiridas ou agravadas pelas atividades de trabalho desenvolvidas pela aluna, acompanhadas de fatores emocionais, como a timidez, a tensão em função das atividades acumuladas além do trabalho, como transporte de crianças, atividades domésticas e familiares e a participação em grupos organizados (igrejas, filantropia, estudos para concursos). Além da sobrecarga de peso corporal causada pelo alimento moderno, que é prático e hipercalórico, as instalações inadequadas do ambiente de trabalho que sobrecarregam e tencionam a musculatura, o ficar de pé ou sentada na mesma posição por longos períodos ou durante toda a jornada de trabalho, e o transporte de pesos e a execução de atividades domésticas em posturas inadequadas entre outras atividades relatadas de forma dialogada.

Atividades estas que levam, pela dor e mal estar que se instalam de forma lenta e gradual até se tornarem constantes, as alunas a se submeterem a diversas sessões de fisioterapia, e após, a busca da chamada manutenção da ausência da dor, feita através da atividade física postural personalizada. Dores que, conforme Knoplich (1995), são causadas pela falta de adaptação, física e psíquica, e pelo tipo de vida moderna que reflete no fato de os músculos desempenharem suas funções tensos e rígidos.Quanto à atividade profissional as alunas se organizam conforme Tabela III. 
Tabela III - Profissão; QT = Quantidade de alunas; FEM = Faixa etária média da comunidade estudada; LMÍN = Limite mínimo e LMÁX = Limite máximo.

\begin{tabular}{|l|c|c|c|c|}
\hline $\boldsymbol{P R O F I S S \tilde { A } \boldsymbol { O }}$ & $\boldsymbol{O T}$ & $\boldsymbol{F E M}$ & $\boldsymbol{L M I N}$ & LMÁ $\boldsymbol{X}$ \\
\hline Administradora & 2 & 42 & 34 & 50 \\
\hline Advogada & 4 & 41,5 & 23 & 53 \\
\hline Analista de Sistemas & 1 & 35 & 35 & 35 \\
\hline $\begin{array}{l}\text { Aposentada (sem } \\
\text { profissão definida) }\end{array}$ & 2 & 58 & 53 & 63 \\
\hline Arquiteta & 2 & 36,5 & 28 & 45 \\
\hline Arte Terapeuta & 1 & 48 & 48 & 48 \\
\hline Assistente Social & 2 & 46 & 41 & 51 \\
\hline Auditora & 1 & 47 & 47 & 47 \\
\hline Bancária & 6 & 41,6 & 36 & 46 \\
\hline Bancária (Aposentada) & 1 & 53 & 53 & 53 \\
\hline Cabeleireira & 1 & 45 & 45 & 45 \\
\hline Comerciária/Empresária & 7 & 50 & 37 & 60 \\
\hline Contadora(aposentada) & 1 & 70 & 70 & 70 \\
\hline Corretora de Imóveis & 1 & 50 & 50 & 50 \\
\hline Odontóloga & 9 & 44 & 25 & 64 \\
\hline Dona de Casa & 14 & 50,85 & 27 & 73 \\
\hline Engenheira Agrônoma & 1 & 49 & 49 & 49 \\
\hline Engenheira Civil & 5 & 40,4 & 31 & 46 \\
\hline Escrevente Oficializada & 1 & 42 & 42 & 42 \\
\hline Esteticista & 2 & 58 & 56 & 60 \\
\hline Estudante & 23 & 21,9 & 14 & 47 \\
\hline Farmacêutica & 1 & 46 & 46 & 46 \\
\hline Fiscal (aposentada) & 1 & 61 & 61 & 61 \\
\hline Fonoaudióloga & 1 & 31 & 31 & 31 \\
\hline Funcionária Pública & 9 & 46,3 & 30 & 65 \\
\hline Gerente de Salão & 1 & 30 & 30 & 30 \\
\hline Industriária & 1 & 54 & 54 & 54 \\
\hline Jornalista & 1 & 39 & 39 & 39 \\
\hline Médica Ginecologista & 2 & 42,5 & 40 & 45 \\
\hline Médica Clinica Geral & 1 & 45 & 45 & 45 \\
\hline Médica Pediatra & 1 & 39 & 39 & 39 \\
\hline
\end{tabular}




\begin{tabular}{|l|c|c|c|c|}
\hline Farmacêutica & 1 & 46 & 46 & 46 \\
\hline Fiscal (aposentada) & 1 & 61 & 61 & 61 \\
\hline Fonoaudióloga & 1 & 31 & 31 & 31 \\
\hline Funcionária Pública & 9 & 46,3 & 30 & 65 \\
\hline Gerente de Salão & 1 & 30 & 30 & 30 \\
\hline Industriária & 1 & 54 & 54 & 54 \\
\hline Jornalista & 1 & 39 & 39 & 39 \\
\hline Médica Ginecologista & 2 & 42,5 & 40 & 45 \\
\hline Médica Clinica Geral & 1 & 45 & 45 & 45 \\
\hline Médica Pediatra & 1 & 39 & 39 & 39 \\
\hline Pecuarista & 1 & 32 & 32 & 32 \\
\hline Professora & 12 & 45,75 & 36 & 63 \\
\hline Professora(aposentada) & 1 & 61 & 61 & 61 \\
\hline Psicóloga & 4 & 44 & 40 & 480 \\
\hline Relações Públicas & 2 & 40 & 34 & 43 \\
\hline TOTAL & 126 & 45,18 & 40,6 & 61,97 \\
\hline
\end{tabular}

Na busca pela "manutenção da ausência da dor", as alunas, em grande parte, conseguiram pelo ambiente motivador um aumento da autoestima, a própria correção postural parcial, a manutenção da ausência da dor, a satisfação e o bem-estar para a execução de suas atividades diárias e de trabalho, redescobrindo o corpo enquanto unidade indissociável.

\section{COMENTÁRIOS FINAIS}

Conclui-se que, com a mecanização e instrumentalização do humano no processo evolutivo, o indivíduo tem se tornado um apêndice de equipamentos e do próprio ambiente de trabalho, levado, pelo desempenho e produtividade, a uma busca frenética do ter. Isto o torna suscetível a lesões muitas vezes irreversíveis, podendo quando muito ser minimizadas por uma atividade orientada e direcionada, na qual se entende por atividade individualizada não apenas a atividade com um indivíduo, mas sim o trabalho direcionado ao individual, buscando a integração da educação corporal, com o convívio em grupo, considerando desejos e limitações, além de problemas posturais. 
A partir de tais considerações, entendemos, conforme Tribastone (2001), que o movimento humano não é só o impulso de um conjunto de alavancas, mas a expressão de sua totalidade. Este movimento, nas concepções atuais, apresenta-se como uma forma do pensamento e como expressão de um gesto de natureza interior.

\title{
Case Study: individualized body education
}

\begin{abstract}
This study is the result of a research work that aims at rethinking and rediscussing individualized physical activity practices. In this context, it brings a new viewpoint to the importance of respecting individuality in its biological, structural, and emotional aspects, and the integration and construction of meaning that can give a sense of direction to the quality of life. This study reports a field research work conducted at the Centro de Trabalho Muscular e Postural (Center for Muscle and Posture Work), from 1998 to 2002, that had, as its theoretical basis, the humanistic approach in pedagogy, as described in the book "Metodologia do Ensino de Educação Física" (Methodology of Physical Education Teaching), characterized by the presence of philosophical principles about human beings and their identity, value, and integral body education.
\end{abstract}

KEY WORDS: Education - Body - Posture - Environment.

Estudio de caso - educacion corporal individualizada

\section{RESUMEN}

El presente estudio, es el resultado de una investigación, el mismo tiene como objetivo relatar a través de un trabajo de campo realizado en el Centro de Trabajo Muscular y Postural en los años de 1998 a 2002, teniendo como base teórica, el movimiento dicho "humanista" en la pedagogía, que conforme el libro Metodología de la Enseñanza de Educación Física, se caracteriza por la presencia de principios filosóficos en torno al ser humano, su identidad y valor, la educación corporal integral, el repensar de la práctica y el accionar de discusiones acerca de la gimnasia individualizada. En este contexto el mismo trae bajo una nueva óptica la importancia del respeto a la individualidad biológica, estructural y emocional, en la integración y construcción de significados, que puedan dar sentido la cualidad de vida.

PALABRAS-CLAVE: Educación - Corporal - Postural - Ambiente.

\section{REFERÊNCIAS}

DAOLIO, Jocimar. Da cultura do corpo. Campinas: Papirus, 1994. 
FREIRE, João Batista. Corpo e Alma. São Paulo: Summus, 1991.

KNOPLICH, José. Viva bem com a coluna que você tem. São Paulo: Ibrasa, 1995.

KATCH, Frank I.; MCARDLE, Willian D. Nutrição, exercício e saúde, Rio de Janeiro: Medsi, 1996.

MERCÚRIO, Ruy. Dor nas costas nunca mais. São Paulo: Manole, 1997.

MARZZOCO, Anita; TORRES, Bayardo Baptista. Bioquímica Básica. Rio de Janeiro: Guanabara, 1990.

TRIBASTONE, Francesco. Tratado de exercícios corretivos.

Barueri: Manole, 2001.

WEINECK, Jungen. Biologia do esporte. São Paulo: Cortez, 2000.

Recebido em: novembro de 2003.

Aprovado em: dezembro de 2003.

Endereço para correspondência

Celisa Laureano Prata Cardoso

E-mail: celisa_laureano@hotmail.com

Av. Quitandinha, Qd. 88, Lt. 08. Setor Jaó - Goiânia - Go

CEP: 74673-060 